\title{
A DIMENSÃO COLETIVA DO TRABALHO DOCENTE: UMA EXPERIÊNCIA EM DUAS ESCOLAS MUNICIPAIS DE BELO HORIZONTE
}

\begin{abstract}
Lídia Campos Gomes Boy*
Adriana Maria Cancella Duarte**

RESUMO: Este artigo apresenta a síntese dos resultados de uma pesquisa sobre o trabalho coletivo entre docentes da rede pública municipal de Belo Horizonte. A análise recai sobre estudos efetuados a respeito da dimensão coletiva do trabalho, que abarca a pluralidade conceitual desse termo, assim como a forma de trabalho colaborativo e os tipos de colaboração entre docentes. O material empírico foi obtido por meio de estudo documental e entrevistas realizadas com docentes em duas escolas municipais de Belo Horizonte. Os resultados revelam distintas formas de se conceber e de se nomear o trabalho coletivo entre os docentes das escolas investigadas, cabendo ressaltar que foi possível constatar diferentes formas de colaboração, com objetivos diversos e consequências distintas. No contexto analisado, de acordo com a percepção dos professores, as práticas coletivas se tornam cada vez mais escassas e se traduzem em discussões de aspectos imediatos e de curto prazo que envolvem o trabalho docente.
\end{abstract}

Palavras-chave: Trabalho docente. Trabalho coletivo. Trabalho colaborativo. Rede Municipal de Educação de Belo Horizonte.

\footnotetext{
* Mestre em Educação pela Universidade Federal de Minas Gerais (UFMG); Professora da Rede Municipal de Educação de Belo Horizonte (RME-BH) e Membro do Grupo de Pesquisa: Política Educacional e Trabalho Docente (GESTRADO) da Universidade Federal de Minas Gerais (UFMG). Email: lidiaboy@gmail.com * * Doutora em Educação pela Universidade Federal de Minas Gerais (UFMG); Professora Associada do Departamento de Administração Escolar da Faculdade de Educação de Minas Gerais (UFMG) e Vice-Coordenadora do Grupo de Pesquisa: Política Educacional e Trabalho Docente (GESTRADO) da Universidade Federal de Minas Gerais (UFMG). Email: dri-duarte58@gmail.com
} 
THE COLLECTIBLE DIMENSION OF TEACHING AS A WORK: THE EXPERIENCE OF TWO SCHOOL IN BELO HORIZONTE COUNTY

\begin{abstract}
This article presents a synthesis of results of a researching on collectible work among teachers of the public education in Belo Horizonte county. The analysis relies over studies made about the collectible dimension of work, which includes the conceptual plurality of the term, as well as the form of collectible work and the types of collaboration among teachers. The empirical material was obtained by means of documental study and interviews made with teachers in two schools in Belo Horizonte county. The results reveal distinct ways of conceiving and nominating the collective work among teachers from the investigated schools and it is important to mention that different forms of collaboration with several objectives and distinct consequences are possible to observe. Within the analyzed context, according to teachers' perception, the collective practice is becoming increasingly scarcer to translate into discussions of immediate and temporary aspects which involve the teaching work.
\end{abstract}

Keywords: Teacher's work. Collective Work. Collaborative Work. Public Education in Belo Horizonte County.

\title{
INTRODUÇÃO
}

Este artigo apresenta a síntese dos resultados de uma pesquisa sobre o trabalho coletivo entre docentes da Rede Municipal de Educação de Belo Horizonte (RMEBH). A dimensão coletiva do trabalho docente vem sendo objeto de pesquisa de alguns autores e é considerada uma temática emergente, considerando-se que as noções de trabalho em conjunto, de colaboração entre docentes e de trabalho coletivo tiveram um relevo nas mudanças ocorridas na gestão, na organização escolar e no trabalho docente decorrentes das reformas educacionais dos anos de 1990 e 2000, que pregavam mecanismos mais coletivos e participativos, amparados no princípio de gestão democrática da educação.

O modo de organização do trabalho docente, relativamente solitário, tem sido questionado nos últimos 30 anos, em diversos países no mundo, a partir dessas mudanças. Dentre elas, Borges (2010) destaca a multiplicidade de tarefas que os docentes têm sido chamados a exercer, o alargamento do público a ser atendido nas escolas, cada vez mais diversificado e heterogêneo do ponto de vista socioeconômico, cultural e étnico, assim como a emergência de um pessoal técnico não docente que vem surgindo no meio escolar (técnicos de disciplina, seguranças, psicólogos, dentre outros). A isso a 
autora acrescenta as alterações no entendimento da missão da escola; as reformas nos programas escolares pautadas no desenvolvimento de competências1; os princípios que têm norteado os saberes escolares; e as exigências por resultados atribuídas às escolas e ao coletivo de professores. Por fim, essa autora salienta as alterações nas relações de poder nos estabelecimentos escolares, que vêm enfatizando a horizontalidade das relações e a equipe-escola como unidade responsável pela interpretação, a adaptação, a negociação e mesmo a criação de regras e de uma cultura próprias.

No contexto brasileiro, a década de 90 contemplou um movimento de reformas educacionais que, em sua ordem legal, pregava o trabalho coletivo por meio da implantação de princípios democráticos no interior das escolas, propondo novos modelos de gestão do ensino público voltados a formas mais participativas no contexto escolar, com o envolvimento do professor na gestão da escola; planejamento conjunto; elaboração do projeto políticopedagógico; preparação de projetos interdisciplinares; participação em instâncias de decisão da escola (assembleias, colegiados, conselhos) (AUGUSTO, 2004).

$\mathrm{Na}$ revisão bibliográfica efetuada para esta pesquisa, não foi encontrado nenhum trabalho que tenha se proposto a investigar, como objeto central, a dimensão coletiva do trabalho docente nas escolas da RMEBH. No entanto, foram localizadas três dissertações de mestrado (FARDIN, 2003; GOMES, 2003; ARAÚJO, 2007) desenvolvidas no âmbito dessa rede e voltadas para a análise do trabalho docente que tocam, de forma breve, na questão do trabalho coletivo. Essas dissertações ressaltam as dificuldades para a realização desse tipo de trabalho e as relacionam com o processo de intensificação ${ }^{2}$ e ampliação das atividades dos docentes, além da escassez de tempos remunerados para este fim.

No sentido de cobrir essa lacuna, a investigação realizada se propôs a responder como as escolas municipais de ensino fundamental de Belo Horizonte estavam se organizando para realizar o trabalho coletivo entre os docentes; como os docentes concebem o trabalho coletivo e qual a percepção deles sobre a forma como estava sendo desenvolvido esse trabalho nas escolas onde atuam. Para responder a essas questões, elegeram-se como campo de pesquisa duas escolas municipais da RMEBH e adotaram-se como instrumento de coleta de dados a observação direta e a entrevista semiestruturada ${ }^{3}$. Foi realizado ainda um estudo documental buscando-se conhecer as políticas e as proposições desse município para o trabalho coletivo 
entre os docentes nas escolas municipais, no período de 1995 a 2010, recorte histórico ${ }^{4}$ efetuado para realização desta pesquisa.

O presente artigo está organizado em três seções, além desta introdução e das Considerações Finais. Na primeira seção, buscouse apresentar a base teórica que orientou a pesquisa; na segunda, as concepções dos docentes e os documentos oficiais da RMEBH sobre o trabalho coletivo; a terceira descreve a organização das escolas para a realização desse tipo de trabalho e apresenta a percepção dos professores sobre essa realização laboral nas unidades em que trabalham. Nestas duas últimas seções, buscou-se relacionar os dados empíricos apresentados com o referencial adotado. As considerações finais retomam e salientam os achados da pesquisa.

\section{TRABALHO COLETIVO DOCENTE: PLURALIDADE CONCEITUAL}

A origem etimológica da palavra "coletivo" remonta ao latim collectivus, que significa: 1. Recolhido; 2. Que é fundado no raciocínio, concludente; 3. Colher juntamente, recolher, juntar, reunir; 4. Ligar juntamente, atar juntamente, reunir, prender; 5 . Ter elementos ligados em conjunto (VICENTINI, 2006, p. 64) (grifos nossos). Dessa forma, a palavra "coletivo", em sua origem etimológica, significa reunir, juntar, ou seja, a agremiação de pessoas.

"Trabalho coletivo" é uma expressão empregada em sentidos diversos. Marx a vincula a vários tipos de trabalho, articulando-os no conjunto da sociedade ${ }^{5}$, isto é, para Marx (1983), a verdadeira alavanca do processo de trabalho global não é mais o trabalhador individual, mas, sim, a força de trabalho socialmente combinada. Nesse sentido, o capitalismo criou o que Marx chama de "trabalhador coletivo", conceito segundo o qual os indivíduos são membros agrupados pelo esforço conjunto de produzir mercadorias (CALLINICOS, 2003).

O trabalho coletivo pode ser entendido ainda como trabalho em equipe, como aparece na forma de organização do trabalho no modelo toyotista ${ }^{6}$ de produção. Esse modelo exige dos trabalhadores a competência do trabalho em equipe, em uma conjuntura em que o processo de produção necessita de maior participação, cooperação e integração dos trabalhadores. Além disso, contrapõe-se às escolas taylorista e fordista, ${ }^{7}$ que privilegiam o método do trabalho individual e especializado (DAL ROSSO, 2006).

No que diz respeito ao trabalho docente coletivo, alguns autores (OLIVEIRA, 2006; VARANI, 2005; SILVA, 2002) negam que se trate de um somatório de trabalhos individuais, como ocorre 
na organização capitalista do trabalho de caráter taylorista/fordista. Nessa perspectiva, para eles, a simples junção de trabalhadores da educação no ambiente escolar não leva ao trabalho conjunto, principalmente se ocorre a segregação de tarefas, de forma que cada um execute uma parte, uma vez que isso, em última instância, levaria à alienação do homem/professor ante sua produção e distanciar-se-ia da construção do processo coletivo (VARANI, 2005).

Como "docente", entende-se aquele profissional que desenvolve algum tipo de atividade de ensino, ou seja, engloba os sujeitos professores e outros profissionais que atuam no processo educativo nas escolas e em outras instituições educacionais (OLIVEIRA; ASSUNÇÃO, 2010). Nesta pesquisa, os sujeitos docentes ficaram circunscritos aos professores regentes de classe, aos coordenadores pedagógicos e aos gestores da escola (diretor e vice-diretor), considerando-se o recorte que se fez para estudar a forma como a escola e os docentes se organizam a fim de promover e realizar atividades de cunho coletivo entre esses profissionais.

Os estudos acerca do trabalho docente coletivo apresentam diferentes possibilidades de organização da ação conjunta como probabilidade de trabalho, manifestadas pelas noções de colaboração, cooperação, colegialidade, parceria, trabalho em equipe, ${ }^{8}$ troca, trabalho em comum, indicando a existência de uma pluralidade conceitual ou nocional do termo "trabalho coletivo" (BORGES, 2010). Todos esses termos são empregados em alguns momentos como sinônimos e, em outros, como desdobramentos de um dos conceitos e com sentidos variados. Borges (2010) atribui a essa pluralidade de definição acerca do trabalho coletivo a sua possibilidade de inserir-se nas diversas atividades dos docentes. Para Tardif e Lessard (2005), tal pluralidade ocorre em razão do contexto escolar, em que as relações são tanto codificadas quanto pautadas sobre amizades, conflitos pessoais, colaborações pontuais e intercâmbios imprevistos.

A questão do trabalho coletivo deve ser pensada, portanto, em suas diferentes possibilidades de configuração e nos fatores que levam a esse ou aquele desenho. Neste texto, vamos focar a discussão do trabalho colaborativo, desenvolvido no item seguinte, como dimensão do trabalho coletivo.

\section{Trabalho colaborativo}

Entre as várias formas de trabalho coletivo, destaca-se o trabalho colaborativo. Diversas pesquisas voltadas para investigar a colaboração entre docentes nos Estados Unidos e na Inglaterra, 
nas escolas elementares e médias, apontam para diferentes formas de colaboração que podem contribuir para o crescimento profissional, a implementação de mudanças, o desenvolvimento escolar e resultados positivos dos estudantes (VAN WESSUM, 1999). Alguns autores aprofundam essa discussão sobre a colaboração no contexto escolar, destacando-se, entre eles, Hargreaves (1998), Fullan e Hargreaves (2001), Tardif e Lessard (2005), Borges (2006, 2010) e Damiani (2008), sobre os quais se procura abaixo sistematizar.

O trabalho colaborativo, definição esta de cunho sociológico, compreende as práticas interativas entre dois ou mais profissionais do ensino que possuem um mesmo estatuto, atuam sobre diferentes objetos - alunos; material didático; estratégias e conteúdos de ensino; projeto de estabelecimento; relação com os pais de alunos, com dirigentes escolares - e assumem a responsabilidade coletiva desse tipo de trabalho (LESSARD, 2005). Fiorentini (2004) se aproxima do entendimento de Borges (2010) ao ressaltar que, no trabalho colaborativo, os membros de um grupo trabalham conjuntamente ("co-laboram") e se apoiam mutuamente, visando atingir objetivos comuns negociados pelo coletivo. Estabelecem relações que tendem à não hierarquização, à liderança compartilhada, à confiança mútua e à corresponsabilidade pela condução das ações.

A colaboração, para Hargreaves (1998) e Fullan e Hargreaves (2001), ocorre a partir do ensino em equipe, da partilha na tomada de decisões e da responsabilidade coletiva como princípio articulador e integrador das ações e do planejamento. Esses autores trabalham com o conceito de culturas colaborativas. Essas não se particularizam "pela organização formal, pelas reuniões ou procedimentos burocráticos. Também não são preparadas para projetos ou eventos específicos" (FULLAN; HARGREAVES, 2001, p. 89). Constituem-se em qualidades, atitudes e valores que são transmitidos e vivenciados nas relações entre os docentes, pautando-se na ajuda, no apoio, na confiança e na abertura. Nesse caso, ocorre a valorização dos indivíduos como pessoas e dos grupos a que pertencem. Nessas culturas, os docentes também desenvolvem a confiança coletiva necessária a uma resposta crítica à mudança, selecionando e adaptando os elementos desta que ajudarão a melhorar o próprio contexto de trabalho e rejeitando aqueles que não o farão (FULLAN; HARGREAVES, 2001).

Para se instaurar uma cultura de colaboração no contexto escolar, fazem-se necessários engajamento e a responsabilização coletiva entre os professores, trabalho de discussão coletiva, de experimentação em sala de aula e avaliação posterior coletiva, além da preocupação 
em garantir tempos e espaços de trabalho coletivo (FULLAN; HARGREAVES, 2001). É importante também que os professores encontrem um sentido em colaborar no trabalho (BORGES, 2006).

\section{Tipos de colaboração entre os docentes}

A existência de colaboração nas relações que envolvem os docentes não implica a existência de uma cultura colaborativa, uma vez que esta se refere a um grau mais elevado do processo de colaboração. Alguns tipos de colaboração devem ser evitados, segundo Fullan e Hargreaves (2001), já que constituem perda de tempo e possuem impactos limitados; outros se organizam como transição a ser ultrapassada na busca de formas mais ambiciosas. Esses autores desenvolvem quatro tipos de colaboração: a balcaniz̧ação, a colegialidade artificial, a colaboração confortável e o trabalho em conjunto.

\section{Balcanização}

A cultura docente balcanizada é constituída pela existência de grupos particulares e isolados de colegas, ou melhor, de subgrupos que geralmente se agregam por trabalhar de maneira mais próxima (mesma disciplina, mesmo ciclo, mesmo ano) (HARGREAVES, 1998; FULLAN; HARGREAVES, 2001). Esses grupos se sentem mais confortáveis, cômodos e complacentes quando trabalham juntos. Trata-se de uma colaboração que se divide, dada a formação de subgrupos menores.

Essa cultura está presente tanto nas escolas a que os autores denominam médias quanto nas de ensino fundamental, prevalecendo fortemente nas primeiras, em que a divisão consiste em disciplinas curriculares. No ensino fundamental, a balcanização pode ser observada por meio da separação dos docentes em diferentes anos e ciclos, sendo rara a existência de uma colaboração entre professores de anos e ciclos diferentes (HARGREAVES, 1998; FULLAN; HARGREAVES, 2001).

No ensino médio, a balcanização foi registrada sustentada pela hegemonia da especialização das matérias, que perpetua os conflitos e as divisões na escola, restringindo a aprendizagem entre profissionais e a troca educativa entre eles (HARGREAVES, 1998). As matérias separadas em diferentes departamentos formam pequenas ilhas, constituídas por um corpo docente fragmentado. Dessa forma, as práticas colaborativas se instalam mais tardiamente no ensino secundário (BORGES; LESSARD, 2007). 
A existência de relações balcanizadas na escola reflete e reforça as diferenças em relação à aprendizagem, às formas de ensinar, aos aspectos das disciplinas e ao próprio currículo. Podem gerar disputas no que diz respeito aos espaços, aos tempos e aos recursos na escola. Além disso, inibem a discussão aberta e podem prejudicar a criação de uma perspectiva da escola em sua totalidade, impedindo o crescimento profissional contínuo dos professores da escola e a sua capacidade de resposta diante das mudanças educacionais (FULLAN; HARGREAVES, 2001).

Isso não significa, segundo Fullan e Hargreaves (2001), desconsiderar a importância da formação de equipes com os colegas que atuam na mesma etapa de ensino, já que essa formação constituise como um passo inicial na formação de culturas colaborativas plenas.

\section{Colegialidade artificial}

A colegialidade artificial, como forma de colaboração, está voltada às práticas formais, burocráticas e obrigatórias de trabalho em conjunto, fixas no tempo e no espaço, além de regulamentadas pela administração, com o objetivo de concretizar a colegialidade nas escolas, a partilha, a aprendizagem e o aperfeiçoamento. Tem também como finalidade criar um ambiente propício ao cumprimento de determinados propósitos administrativos, à implementação de novas técnicas e abordagens externas por meio da cooptação dos professores e da manipulação indireta dos acordos. Geralmente, o trabalho conjunto é imposto administrativamente e de forma inflexível (FULLAN; HARGREAVES, 2001).

Entre as atividades desenvolvidas nesse tipo de colaboração, destacam-se o planejamento conjunto em espaços e tempos reservados para essa tarefa - geralmente nos tempos de preparação, nas reuniões programadas formalmente, nas descrições detalhadas de atividades e programas de formação. Trata-se de formas de colegialidade que obrigam os docentes a trabalharem juntos - muitas vezes, a se reunirem com os pares; quando não há sobre o que discutir, não encorajam os docentes a desenvolverem o trabalho em conjunto (FULLAN; HARGREAVES, 2001).

A colegialidade artificial pode ser um passo inicial para a instauração de uma cultura colaborativa na escola, quando utilizada de forma facilitadora e não controlada, a fim de preparar relações colaborativas mais duradouras entre os docentes, proporcionando o contato entre eles. Essa pode também proporcionar a focalização do trabalho em conjunto (FULLAN; HARGREAVES, 2001). 


\section{Colaboração confortável}

Colaboração confortável é aquela que se restringe aos aspectos práticos, imediatos e de curto prazo que envolvem o trabalho docente. Não atinge, portanto, os aspectos mais profundos da profissão, como, por exemplo, a privacidade da sala de aula dos docentes, isto é, torna-se uma colaboração circunscrita. Nesse tipo de colaboração, procura-se evitar as discussões e os desacordos relativos aos princípios e às práticas de ensino. Consistem, dessa forma, em atividades mais seguras, confortáveis e periféricas aos docentes, como a oferta de conselhos, a troca de dicas e a partilha de materiais, com uma natureza mais imediata, específica e técnica (FULLAN; HARGREAVES, 2001).

Acrescentam-se a essas a revisão conjunta dos recursos e o planejamento do estudo sem a reflexão dos valores, dos objetivos e a consequência do que fazem (HARGREAVES, 1998). Nesse sentido, perdem-se o valor e o propósito daquilo que se ensina e como se ensina, excluindo-se a prática reflexiva sistemática.

\section{Trabalho em conjunto}

O trabalho em conjunto é a forma de colaboração que cria interdependências mais fortes, com responsabilidade partilhada, empenho e aperfeiçoamento coletivos, além de maior disponibilidade de se envolver em atividades de revisão e crítica ao trabalho efetuado (HARGREAVES, 1998). Abrange também a ação comum e a negociação e é orientado por um objetivo comum, envolvendo sempre a resolução de um problema (MÉRINI, 2007). Essa forma de trabalho é caracterizada por Loes (1999) como baseada no desenvolvimento de materiais e atividades com cada professor, no ensino conjunto nas salas de aula e na visita de cada professor às outras salas.

Com base nos tipos de colaboração levantados acima, fez-se necessário identificar e analisar nas escolas pesquisadas a concepção que os docentes tinham acerca do trabalho coletivo, as formas mais complexas e as formas mais simples de colaboração existentes em tais escolas, assim como destacar quais eram as mais comuns e quais eram as mais difíceis de ser construídas e mantidas durante longos períodos de tempo.

\section{CONCEPC̣ÕES ACERCA DO TRABALHO COLETIVO: O PONTO DE VISTA DOS DOCENTES E OS DOCUMENTOS PESQUISADOS}

Os resultados encontrados no estudo empírico revelaram que os docentes participantes da pesquisa concebem o trabalho 
coletivo valendo-se de três importantes interpretações. A primeira está ligada ao entendimento de que esse tipo de trabalho envolve o desenvolvimento e a execução de um projeto coletivo comum a toda a escola, que contemple as propostas pedagógicas e o próprio funcionamento da instituição. Nesse sentido, defendem que a realização do trabalho coletivo dependeria de uma ação global dos profissionais da instituição escolar. Os depoimentos dos docentes que responderam nessa perspectiva expressam que a direção pedagógica, organizacional e política da escola deveria ser orientada por projeto político-pedagógico construído coletivamente. Assim, os profissionais da escola deveriam trabalhar conjuntamente, visando atingir objetivos comuns, negociados pelo seu coletivo. Essa noção sobre o trabalho coletivo se aproxima de algumas características do trabalho colaborativo mencionado por Hargreaves (1998), Fullan e Hargreaves (2001), Fiorentini (2004) e Borges (2010), como o engajamento dos docentes, a discussão coletiva e o trabalho conjunto visando atingir objetivos comuns negociados pelo coletivo da escola.

Outro aspecto ressaltado pelos docentes entrevistados sobre como concebem o trabalho coletivo diz respeito ao grau de envolvimento dos profissionais na gestão escolar, ou seja, no planejamento das ações e na sua execução. Nesse sentido, enfatizaram principalmente a tomada de decisões em conjunto sobre as questões relevantes que envolvem a organização e a gestão da escola. Esse entendimento abrange a partilha de poder e também a responsabilidade coletiva assumida no trabalho.

O trabalho coletivo é entendido ainda pelos docentes entrevistados como aquele que permite compartilhar os saberes e as experiências que os outros professores detêm e também as próprias atividades cotidianas de trabalho, como: troca de ideias, opiniões e sugestões a respeito dos avanços e dos retrocessos dos alunos no que diz respeito à aprendizagem; discussão conjunta a respeito do planejamento, dos métodos de ensino adotados, dos projetos da escola, da avaliação dos alunos e sobre estratégias de melhora nos índices de qualidade; discussões que envolvem a vulnerabilidade social, a indisciplina dos alunos e a falta de interesse destes quanto aos aspectos que envolvem a escola, assim como em relação às famílias, que, segundo os entrevistados, pouco acompanham a vida escolar de seus filhos.

Algumas características do trabalho coletivo presentes nos depoimentos dos docentes participantes da pesquisa seriam o que Tardif e Lessard (2005) definem como "colaboração para o cumprimento de tarefas", ou aquilo que Fullan e Hargreaves 
(2001) designam como "colaboração confortável", conceitos que se restringem aos aspectos práticos, imediatos e de curto prazo que abarcam o trabalho docente, como o apoio pedagógico dado ou recebido de um colega, o planejamento do ensino, a construção e a preparação de material pedagógico.

$\mathrm{Na}$ análise documental efetuada, verificou-se diferença de concepção entre documentos legais do início da década de 90 e do fim dos anos 2000 em relação ao significado de "trabalho coletivo". Os documentos da RMEBH da década de 90, sob a égide da Escola Plural, aproximam-se mais dos conceitos de colaboração desenvolvidos por Fullan e Hargreaves (2001), Tardif e Lessard (2005), Borges (2006, 2010) e Damiani (2008) no que se refere à produção coletiva do conhecimento; ao pensar e ao repensar a prática de forma coletiva; ao trabalho conjunto dos profissionais da escola; à formulação, ao planejamento e à avaliação conjunta de projetos desenvolvidos pelos docentes, assim como à reunião de profissionais em função de uma proposta pedagógica coletiva.

A proposta político-pedagógica da Escola Plural ${ }^{9}$, implantada em 1993, na gestão do prefeito Patrus Ananias, era vista como diferenciadora, porque reformulava as noções de currículo, de processo ensino-aprendizagem, de tempo escolar e de avaliação, adotando a concepção de ciclos de formação humana. A educação por ciclos de formação refere-se à organização do tempo escolar de modo a proporcionar aos alunos o período adequado ao tempo de socialização e formação no convívio entre sujeitos da mesma idade (LIMA, 2000). Nesse sentido, os educandos devem ser agrupados segundo sua idade, supondo-se que a convivência com companheiros da mesma idade facilitaria a socialização, a construção de autoimagens e de identidades. $\mathrm{O} 1^{\circ}$ ciclo (infância) compreende as faixas etárias de 6, 7, 8/9 anos; o $2^{\circ}$ ciclo (pré-adolescência), as faixas etárias de 9,10 , 11/12 anos; e o $3^{\circ}$ ciclo (adolescência), os alunos de 12,13,14/15 anos (BELO HORIZONTE, 1994a) ${ }^{10}$.

Os documentos do fim da década de 2000 vão interpretar o trabalho coletivo como a soma de esforços individuais, ou seja, prescrevem que "o trabalho coletivo não significa que todos devem trabalhar ao mesmo tempo em todas as atividades e conhecimentos escolares, mas cada um deve fazer sua parte, cooperativamente, contribuindo para o alcance de um objetivo comum: o aprendizado e o letramento das crianças" (BELO HORIZONTE, 2009, p. 25). Cabe ressaltar que nesse período surgia, em destaque na mídia, a discussão sobre o fim da proposta pedagógica da Escola Plural ante um novo 
projeto de ensino em Belo Horizonte, que tinha como objetivo tirar a cidade da "nota vermelha" no Índice de Desenvolvimento da Educação Básica (Ideb), que, na última avaliação para medir a qualidade do ensino fundamental, havia obtido desempenho abaixo da média estipulada (TUPINAMBÁS, 2009). Algumas ações, como a volta do boletim escolar tendo como base os conceitos escolares ${ }^{11}$ e o cumprimento de metas rumo a uma escola de resultados, reforçam esse reajuste na proposta pedagógicas da RMEBH e a mudança de concepção sobre o que seria o trabalho coletivo entre os docentes.

\section{CONFIGURAÇÃO DOS TEMPOS ESCOLARES NA RMEBH E TIPOS DE COLABORAÇÃO EXISTENTES NAS ESCOLAS PESQUISADAS}

A organização por ciclos de formação humana na Escola Plural, na década de 90, implicou uma reorganização do trabalho docente, uma vez que alterou os tempos e os espaços escolares, que passaram a ser necessariamente organizados de forma a proporcionar horários para encontros coletivos entre os docentes, em consonância com os documentos da época. Nesse formato, se inserem as reuniões pedagógicas como atribuição do professor, as quais constam no Plano de Carreira dos Servidores da Educação da Prefeitura Municipal de Belo Horizonte, sob a Lei Municipal ${ }^{\circ}$ 7.235, de 27 de dezembro de 1996 (BELO HORIZONTE, 1996).

As reuniões pedagógicas coletivas estavam previstas no Regimento Interno do Ensino Primário já em 1954. Em 1985, as escolas de $1^{\mathrm{a}}$ a $4^{\mathrm{a}}$ série foram autorizadas a realizar reuniões pedagógicas semanais ou quinzenais, sendo que, durante a sua realização, a escola dispensava os seus estudantes (ROCHA, 2009). Tais reuniões eram entendidas como um período diferenciado que proporcionava a formação e o aperfeiçoamento do processo educativo dos docentes, efetivado pela escola (BELO HORIZONTE, 1999). Esse formato de reunião foi mantido nas escolas de $1^{\circ}$ e $2^{\circ}$ ciclos e incorporado por algumas de $3^{\circ}$ ciclo na proposta da Escola Plural.

A Lei de Diretrizes e Bases da Educação Brasileira (LDB) de 1996 (BRASIL, 1996), porém, estabeleceu a ampliação do tempo escolar para a educação básica, fixando uma jornada escolar, no ensino fundamental, mínima de quatro horas diárias de trabalho efetivo em sala de aula (BRASIL, 1996, art. 34). Isso dificultou a manutenção das duas horas semanais utilizadas para a realização de reuniões pedagógicas coletivas, considerando que, ao dispensarem os alunos, as escolas da RMEBH não cumpririam o número de horas 
estipulado para a jornada escolar (BELO HORIZONTE, 1999). A partir de então, iniciou-se uma série de debates acerca dos tempos coletivos na RMEBH, tanto por parte da Secretaria Municipal de Educação (SMED-BH) quanto das escolas e das instituições sindicais: Sindicato dos Trabalhadores em Educação da Rede Municipal de BH (Sind-Rede/BH) e Sindicato Único dos Trabalhadores em Educação de Minas Gerais (Sind-UTE/MG).

No entanto, somente no ano de 2005 a discussão referente aos tempos escolares apresentou-se mais enfática no âmbito da SMED-BH, dos sindicatos e das escolas. Naquele ano, foram publicadas as portarias Belo Horizonte/SMED 226/2004 e 013/2005, a fim de modificar a jornada anual de trabalho, ampliar o calendário escolar e colocar fim às reuniões pedagógicas dentro da jornada semanal, aliadas à dispensa de alunos (ROCHA, 2009). A SMED-BH apresentou propostas para que as reuniões pedagógicas continuassem a existir considerando-se as quatro horas diárias para a aprendizagem dos alunos, por meio de abonos e em horários extraturno da jornada docente ou dentro do próprio turno de trabalho, recomendando que os estudantes fossem acompanhados por agentes educacionais durante as reuniões pedagógicas. A consolidação dessas propostas será apresentada a seguir.

Com base na análise de documentos, na observação em campo e nas entrevistas realizadas, foi possível perceber que as escolas municipais de Belo Horizonte têm se organizado atualmente para a realização do trabalho coletivo entre os docentes por meio de: a) reuniões pedagógicas fora da jornada de trabalho (BELO HORIZONTE, 2010); b) reuniões pedagógicas dentro da jornada de trabalho, com a contratação de oficineiros (recursos do PAP - Projeto de Ação Pedagógica); c) Atividades Coletivas de Planejamento e Avaliação do Trabalbo Escolar-ACPATEs; d) sábados letivos previstos no calendário escolar. Esses são os formatos que garantem, de alguma maneira, os tempos e os espaços de trabalho coletivo atualmente na RMEBH, uma vez que envolvem encontros entre os docentes.

O primeiro tipo - "reuniões pedagógicas fora da jornada de trabalho" - surgiu quando entrou em vigor a Lei Municipal $\mathrm{n}^{\circ}$ 9.815/2010 (BELO HORIZONTE, 2010), que estabeleceu, em seu art. $4^{\circ}$, o Prêmio por Participação em Reunião Pedagógica para os servidores públicos que ocupam cargos da Área de Atividades de Educação e que tenham participado das reuniões pedagógicas em sua unidade escolar. O servidor, para receber o prêmio, é orientado a estar presente a no mínimo duas reuniões pedagógicas por mês, 
com duração mínima de uma hora e 30 minutos cada uma. Para ter direito ao prêmio - que equivale a $\mathrm{R} \$ 100,00$ mensais para os professores municipais -, o servidor deve também ter obtido frequência integral no mês anterior ao da realização da reunião pedagógica, ou seja, as licenças, os afastamentos e as faltas, mesmo quando justificadas, impedem os docentes de receberem o abono ${ }^{12}$.

O formato de reunião pedagógica acima citado aproxima-se da concepção de "colaboração balcanizada" desenvolvida por Hargreaves (1998) e Fullan e Hargreaves (2001), por se tratar de uma colaboração que divide, que se restringe a um pequeno grupo e inibe a discussão de questões mais amplas, dificultando a criação de uma perspectiva de totalidade nas escolas. No caso das escolas estudadas, isso se deve a fatores como as reuniões serem opcionais e gerarem prêmio em dinheiro para os docentes que delas participam; além de ocorrerem em horário extraturno ou aos sábados, isto é, muitos professores não podem participar, já que estudam, ou trabalham, ou têm atividades particulares para desenvolver (principalmente familiares) nos horários em que as reuniões ocorrem. Ainda, há o desestímulo para o professor que tenha faltado algum dia no mês, já que não irá mais receber o abono e, em função disso, deixará de comparecer às reuniões. Abaixo, encontram-se depoimentos dos docentes que, em síntese, mostram a superficialidade e a descontinuidade das discussões, a fragmentação e também a "invasão" das questões profissionais no tempo da vida privada:

[...] A gente acaba não indo muito a fundo nas discussões [...]. Quase nunca é passado para o grupo de docentes o que foi discutido (Professor de Educação Física, $3^{\circ}$ ciclo, Escola B).

[...] Uns vêm de tarde, outros vêm à noite, em grupos separados; não tem aquele elo entre o que é discutido em um e no outro. [...] Eu não considero tempo coletivo (Professor de Geografia, $3^{\circ}$ ciclo, Escola B).

[...] Tiraram a reunião do turno porque a justificativa é que o aluno não pode ficar fora da escola. Mas eu posso vir fora do horário, me desdobrar? Todo mundo tem sua vida pessoal, tem seus problemas, tem suas doenças, tem seus tratamentos, tem sua família, tem de tudo na hora que você sai daqui, não são só os pais e mães dos nossos alunos, nós também temos [...]. Sem contar que você já fica um dia inteiro no trabalho, que é cansativo, e ainda vai ficar depois pra discutir questões, sendo que você já está nas últimas forças do dia pra discutir (Professora do $1^{\circ}$ ano do $1^{\circ}$ ciclo, Escola A).

Outro importante comentário dos docentes sobre esse primeiro tipo de reunião se refere ao abono, que, segundo eles, está fora das garantias trabalhistas e previdenciárias, uma vez que não é incorporado aos vencimentos, conforme depoimento abaixo: 
Primeiro, esses R $\$ 100,00$ são uma bonificação à parte do seu salário, não é salário. Então, ele não vai valer no seu salário para você aposentar, para quinquênio, para nada. Ele é um abono; da mesma maneira que foi colocado, ele pode ser tirado a qualquer hora [...]. Então, se você avaliar financeiramente, é meio ilusório. Parece que você está ganhando, mas, no fim, acaba que o Imposto de Renda, isso foi até o Sindicato que informou, o Imposto de Renda come uma boa parte dele; então, financeiramente ele não é atrativo (Professora do $1^{\circ}$ ano do $1^{\circ}$ ciclo, Escola $\mathrm{A}$ ).

Em relação ao segundo modelo de reunião - "dentro da jornada de trabalho por meio da verba do PAP, com a contratação de oficineiros" -, foi proposto pela SMED-BH, com base no parecer do CNE/CEB 2005, que recomendou que a realização de reuniões pedagógicas dentro do turno de trabalho deveria prever que os estudantes fossem acompanhados por agentes educacionais. A estratégia encontrada pela escola pesquisada foi utilizar recursos do PAP, que permitem a contratação de profissionais para a formação dos docentes e também para a atuação com os alunos em dias letivos, o que viabilizaria as reuniões entre os docentes dentro da jornada de trabalho. Essa perspectiva criou uma expectativa de retorno às reuniões coletivas no interior da escola e no tempo reservado para o trabalho. No entanto, esse segundo tipo de reunião, embora busque a criação de espaços de discussão coletiva dentro da jornada de trabalho, também tem as suas dificuldades de execução; primeiro, pela imprevisibilidade do recebimento da verba, ou seja, a chegada à escola dos recursos do PAP para a contratação dos oficineiros e a consequente liberação dos docentes para participarem de reuniões.

\footnotetext{
É final de maio; o recurso deveria ter chegado lá em fevereiro [...]. A prefeitura não fez o repasse, pelo menos, essa é a informação. [...] Aí fica amarrado nessa questão, porque nem sempre a escola tem essa disponibilidade pra contratar os oficineiros, porque tem uma burocracia no contrato, tem o dinheiro que não vem às vezes; nesse agora recente, o dinheiro não veio ainda (Professor do $3^{\circ}$ ciclo, História, Escola A).
}

Em segundo lugar, porque as oficinas só podem durar quatro horas ao mês, por turma, o que obriga as reuniões a seguirem o mesmo calendário e a mesma duração das oficinas. A Coordenação Pedagógica da escola, que organiza tais reuniões, tem que levar em conta o número de oficineiros disponíveis para entreter os alunos, o tempo máximo mensal de duração das oficinas e procurar critérios para organizar a reunião de professores. A saída encontrada tem sido constituir grupos de docentes de determinado ciclo, ou por ano de cada ciclo, e propor o encontro entre eles, ou seja, organizando o que é possível dentro desse quebra-cabeça e com o que se tem disponível. 
Outra dificuldade é que se torna possível, com essa carga horária de quatro horas, fazer uma ou no máximo duas reuniões mensais, o que tem se mostrado pouco eficaz em relação à complexidade dos temas que precisam ser tratados e à continuidade necessária aos debates que se iniciam em cada uma delas.

Em relação à questão do número de reuniões pedagógicas, você não consegue fazer isso semanalmente igual antigamente. Você não consegue organizar nem uma mensal, e olhe lá se dá para ser bimestral [...]. A questão é que você tem que enxugar muito. Um tempo muito restrito, porque acontece de forma bem espaçada, quando acontece. Então, fica complicado, você tem uma pauta enorme, e o tempo é insignificante (Professor de Práticas Agrícolas, $3^{\circ}$ ciclo, Escola A).

A terceira modalidade de reunião - "Atividades Coletivas de Planejamento e Avaliação do Trabalho Escolar - ACPATEs" foi assegurada aos professores da RMEBH pela Lei Municipal $n^{\circ}$ 7.577, de 21 de setembro de 1998 (BELO HORIZONTE, 1998), como horário legalmente obrigatório de estudo, planejamento e avaliação do trabalho pedagógico por meio da utilização de $20 \%$ da jornada semanal do professor municipal, de 22 horas e 30 minutos, excluído o tempo de recreio.

As atividades coletivas planejadas para serem realizadas em duplas ou em trios de docentes que ministram a mesma disciplina ou atuam no mesmo ano do mesmo ciclo englobam principalmente a troca de informações sobre determinados alunos ou determinadas turmas; planejamento e preparação de atividades comuns ou permuta de material didático. Essas atividades estão ligadas à colaboração para o cumprimento de tarefas ou àquela que se denomina "colaboração confortável", indicadas por Fullan e Hargreaves (2001), que se referem aos aspectos práticos, imediatos e de curto prazo que envolvem o trabalho diário do docente.

No entanto, segundo os docentes entrevistados, no momento das ACPATEs, a colaboração entre os docentes tem se tornado aspecto secundário, considerando-se que são as questões individuais do trabalho docente que têm se sobressaído nesses momentos, ou seja, os docentes fazem aquilo que é mais urgente, conforme depoimento abaixo.

É o tempo que o professor tem para preparar as suas atividades, a sua semana, a sua etapa, corrigir os seus exercícios, as suas provas. É o tempo individual do professor, que deveria ser coletivo dentro da sua área, mas, pelas condições, circunstâncias... não dá [...]. No dia que você está de projeto, tem tanta demanda para você que não sobra tempo pra que você possa discutir coletivamente alguma demanda da escola (Professor do $3^{\circ}$ ciclo, Ciências, Escola A). 
Apesar de se constituírem como um momento de atividades extraclasse, os tempos destinados às ACPATEs têm sido com frequência tomados pela substituição de colegas ${ }^{13}$ que faltam (absenteísmo) e pelas licenças de curto prazo, além da própria rotatividade docente, que acaba resultando em lacunas em determinado horário/ disciplina na escola. Nota-se que os poucos momentos observados como possibilidade de desenvolvimento do trabalho conjunto entre docentes que atuam no mesmo ciclo, ou no mesmo ano do ciclo, ou com a mesma disciplina, ficam assim prejudicados pelas demandas mais imediatas da escola: "[...] é difícil um dia que a gente tenha o quadro completo de professores para trabalhar. Como não tem, vão todos para as salas de aula, e não tem reunião. [...] Depois que chegaram mais professores efetivos, melhorou um pouquinho [...]" (Coordenadora Pedagógica, $3^{\circ}$ ciclo, Escola B).

A quarta modalidade de reunião, os "sábados letivos", foi apontada pelos docentes como momento propício aos encontros entre professores de todos os turnos de trabalho. Essas reuniões são reservadas à organização de demandas do cotidiano escolar e ao repasse de informes da escola e da SMED-BH; porém, ocorrem com frequência reduzida (em média, quatro vezes ao ano), visto que as datas devem se encontrar estipuladas no calendário escolar.

\section{CONSIDERACְ̃̃ES FINAIS}

Salienta-se, como indicado anteriormente, a diferença de concepção nos documentos legais em relação ao significado do trabalho coletivo. Enquanto os documentos da RMEBH da década de 90, sob a égide da Escola Plural, aproximam-se mais do conceito de colaboração que envolve o trabalho em conjunto, os documentos do fim da década de 2000 vão interpretar o trabalho coletivo como a soma de esforços individuais. Portanto, houve uma mudança fundamental na forma de pensar a organização e a realização do trabalho coletivo, pelo menos no que se encontra registrado nos documentos oficiais, antes mesmo de se fortalecer e implementar de fato aquilo que estava proposto para a década de 90 , sinteticamente apresentado neste artigo. Além disso, os resultados apurados no estudo empírico levaram a problematizar as características das reuniões pedagógicas conforme formatadas atualmente na RMEBH, em relação à periodicidade, à duração e à imprevisibilidade de sua garantia.

Em relação ao primeiro modelo, o extraturno, pôde-se constatar uma intensificação do trabalho docente, considerando-se 
a expansão da jornada, com remuneração inadequada, denominada de "prêmio", tanto ao que se refere ao seu valor quanto às exigências para o seu recebimento. Verificou-se ainda a dificuldade de participação daqueles que possuem outras atividades de trabalho, de formação continuada ou de âmbito pessoal nos horários agendados para esse tipo de reunião. Essas dificuldades acabam por interferir na dinâmica dessas reuniões, diminuindo o quadro de presença dos docentes em cada uma delas e impossibilitando a continuidade das discussões iniciadas, conforme a percepção dos docentes entrevistados. Nas observações realizadas, pôde-se perceber também que se privilegiam como temáticas para esses encontros questões mais imediatas relativas ao trabalho pedagógico, à questão da disciplina dos alunos e ao calendário escolar.

No que se refere à forma como estão sendo concretizadas as ACPATEs, verificou-se que o tempo reservado para essas atividades têm sido ocupado muitas vezes com a realização de demandas individuais inerentes ao trabalho do professor em detrimento das atividades coletivas, além de ser tomado com frequência para a cobertura dos colegas que faltam (absenteísmo) ou que tiram licenças de curto prazo. Soma-se a isso a própria rotatividade docente nas escolas, que acaba deixando em descoberto determinado horário/disciplina na escola, sendo os professores que estão no horário de ACPATE chamados para cobrir mais essa lacuna. Dessa forma, os momentos de ACPATE acabam por ficar prejudicados pelas demandas imediatas da escola, esvaziando-se as possibilidades, nos espaços remunerados e previstos na organização escolar, de trabalho coletivo destinado a tratar de questões coletivas da escola, dos ciclos e das disciplinas.

Os docentes veem como um direito as reuniões pedagógicas dentro da jornada de trabalho e consideram que a estratégia de utilização da verba do PAP para esse fim, diante da escassez de tempos propícios ao trabalho conjunto na escola, poderia ser uma saída dentro das possibilidades atuais e apresentaram uma boa expectativa em relação a elas. Nessas reuniões, tem se aproveitado o tempo para se discutir e construir o possível de forma conjunta entre os docentes presentes. No entanto, outros problemas, como o atraso das verbas para a contratação dos oficineiros e a descontinuidade dos processos iniciados em cada reunião, além do pouco tempo previsto para a sua realização, tornam esse tipo de reunião insuficiente para suprir as carências que emergem e demandam o trabalho em conjunto. 
Foi possível observar que a falta de tempo destinado ao trabalho coletivo tem tido como consequência a fragmentação do trabalho e o isolamento dos docentes, levando a incertezas em relação ao ensino, já que, cada vez mais, há menos espaços coletivos para os debates das novas demandas da RMEBH para as escolas. Na observação em campo, foi possível notar que ações individualizadas, voltadas para atender às demandas imediatas da própria turma, eram priorizadas em detrimento das ações conjuntas.

Para finalizar, valendo-se dos tipos de colaboração levantados neste artigo, é necessário considerar que as culturas colaborativas são complexas e difíceis de ser construídas e mantidas durante longos períodos de tempo. No contexto analisado, as práticas coletivas, como descritas pelos docentes quando a conceberam, tornam-se cada vez mais distantes do cotidiano escolar. Foi possível registrar práticas colaborativas mais simples e circunscritas, que abrangem discussões de aspectos imediatos e de curto prazo envolvendo o trabalho docente, mesmo que entrecortadas por tempos e espaços precários e insuficientes. Conforme já constatavam Hargreaves (1998) e Loes (1999) em suas pesquisas, as formas mais simples de colaboração nas escolas são mais comuns do que as mais complexas.

Percebe-se que essas formas mais complexas de colaboração são descritas pelos docentes quando concebem o trabalho coletivo indo além dos aspectos pedagógicos, ou seja, eles o entendem como partilha de poder, participação na gestão, criação de projeto pedagógico e organizacional comum, partilha do saber, troca de experiências, formação democrática do aluno, além de condições de trabalho para realizá-los. Nessa perspectiva, o que foi encontrado nas duas escolas pesquisadas está ainda longe de se concretizar como tal, apesar dos esforços empreendidos.

Outro aspecto importante destacado pelos professores se refere às condições de trabalho, que não favorecem o trabalho coletivo, uma vez que todas as atividades têm de ser desenvolvidas durante a jornada semanal, de 22 horas e 30 minutos, ou ocorrer no horário extraturno ou nos sábados, o que significa que o professor do ensino fundamental da RMEBH não possui jornada compatível com as exigências postas pelo aparato legal para o seu trabalho.

Nesse sentido, verificou-se que o que ocorre de fato no interior das escolas para a concretização do trabalho colaborativo entre os docentes são estratégias e arranjos dos próprios docentes e da gestão escolar, por meio da utilização dos momentos 
possíveis de se organizarem via reuniões formais e em momentos informais (recreio, antes do início das aulas, após as aulas). Notase uma busca a fim de favorecer ou, de alguma forma, preservar algum tempo para encontro entre grupos de docentes diante da escassez de tempos propícios na jornada de trabalho para reuniões permanentes em condições adequadas.

\section{REFERÊNCIAS}

ANTUNES, R. Os sentidos do trabalho: ensaio sobre a afirmação e a negação do trabalho. São Paulo: Boitempo, 1999.

ARAUJO, S. Ser professor coordenador pedagógico: sobre o trabalho docente e sua autonomia. 2007. Dissertação (Mestrado em Educação) - Faculdade de Educação, Universidade Federal de Minas Gerais, Belo Horizonte, 2007.

AUGUSTO, M. H. Trabalho docente e organização escolar na rede estadual de ensino em Minas Gerais. 2004. Dissertação (Mestrado em Educação) - Faculdade de Educação, Universidade Federal de Minas Gerais, Belo Horizonte, 2004.

BELO HORIZONTE. Secretaria Municipal de Educação. Escola Plural: uma nova escola em formação. Belo Horizonte: SMED, 1994.

. Secretaria Municipal de Educação. Escola Plural: proposta político-pedagógica. Belo Horizonte: SMED, 1994a.

. Secretaria Municipal de Educação. Ciclos de formação e trabalho coletivo dos professores. Belo Horizonte: SMED, 1996.

Lei Municipal no 7.235, de 27 de dezembro de 1996. Dispõe sobre o quadro especial da Secretaria Municipal de Educação, institui o Plano de Carreira dos Servidores da Educação da Prefeitura Municipal de Belo Horizonte, estabelece a respectiva tabela de vencimentos e dá outras providências. Diário Oficial do Município, Belo Horizonte, 1996.

. Lei Municipal n 7.577 , de 21 de setembro de 1998. Concede benefícios a servidores, define a jornada de trabalho dos servidores da educação e dá outras providências. Diário Oficial do Município, Belo Horizonte, 1998.

SMED, 1999.

. Secretaria Municipal de Educação. Ciclos de formação na Escola Plural. Belo Horizonte:

. Secretaria Municipal de Educação. A construção pedagógica do tempo. Belo Horizonte: SMED, 1999b.

. Secretaria Municipal de Educação. Infância: o primeiro ciclo de idade de formação. Belo Horizonte: SMED, 1999c.

. Secretaria Municipal de Educação. Carta de Princípios da Rede Municipal de Educação de Belo Horizonte. Belo Horizonte: SMED, 2001.

Secretaria Municipal de Educação. Trabalho coletivo dos profissionais da educação. Belo Horizonte: SMED, 2002.

Portaria SMED n. 226/2004, Dispõe sobre os parâmetros para elaboração do Calendário Escolar de 2005 das unidades escolares Educação de Belo Horizonte, que atendem Ensino Fundamental, Ensino Médio, Educação de Jovens e Adultos. Diário Oficial do Municipio, Belo Horizonte, 2004. 
Portaria SMED n. 013/2005. Dispõe sobre os parâmetros para elaboração do Calendário Escolar de 2005 das unidades escolares da Rede Municipal de Educação de Belo Horizonte que atendem aos Ensinos Fundamental e Médio, Educação de Jovens e Adultos e Educação Especial. Diário Oficial do Município, Belo Horizonte, 2005.

Secretaria Municipal de Educação. Tempos escolares: construindo possibilidades. Belo Horizonte: SMED, 2005a.

Secretaria Municipal de Educação. Proposições curriculares para a Rede Municipal de Belo Horizonte. Belo Horizonte: SMED, 2009.

Lei Municipal 9.815, de 18 de janeiro de 2010. Concede reajustes remuneratórios aos servidores e empregados públicos da Administração Direta e Indireta do Poder Executivo e dá outras providências. Diário Oficial do Município, Belo Horizonte, 2010.

. Lei Municipal ${ }^{\circ} 10.671$, de 25 de outubro de 2013. Concede reajustes remuneratórios aos servidores e empregados públicos da administração direta e indireta do executivo e dá outras providências. Diário Oficial do Município, Belo Horizonte, 2013.

BORGES, C. Colaboração docente e reforma dos programas escolares em Quebec. Educação em Revista, Belo Horizonte, v. 44, p. 229-255, dez. 2006.

Trabalho coletivo. In: OLIVEIRA, D. A.; DUARTE, A. M. C.; VIEIRA, L. M. F. Dicionário: trabalho, profissão e condição docente. Belo Horizonte: UFMG/Faculdade de Educação, 2010. (CD-ROM)

BORGES, C; LESSARD; C. Que'arrive-t-il quand la collaboration enseignante devient une norme? In: MARCEL, J.; DUPRIEZ, V.; BAGNOUD. D; TARDIF. M. Coordonner, collaborer, coopérer: de nouvelles pratiques enseignantes. 1. ed. De Boeck, 2007.

BRASIL. Lei no 9.394, de 20 de dezembro de 1996. Lei de Diretriz̧es e Bases da Educaşão Brasileira (LDB). Brasília, 1996.

CALLINICOS, A. Testando a teoria social através da política: Pierre Bourdieu e Anthony Giddens. Margem Esquerda - Ensaios Marxistas (n. 2). São Paulo: Boitempo, 2003. p. 52-67.

Jornada de trabalho: duração e intensidade. Ciência e cultura: temas e tendências: Revista da Sociedade Brasileira para o Progresso da Ciência, São Paulo, v. 58, n. 4, p. 31-34, out./dez. 2006.

DAMIANI, M. F. Entendendo o trabalho colaborativo em educação e revelando seus benefícios. Educação em Revista, Belo Horizonte, n. 31, p. 213-230, 2008.

FARDIN, V. L. Tecendo análises sobre o trabalho docente nos ciclos de formação da Escola Plural. 2003. Dissertação (Mestrado em Educação) - Faculdade de Educação, Universidade Federal de Minas Gerais, Belo Horizonte, 2003.

FIORENTINI, D. Pesquisar práticas colaborativas ou pesquisar colaborativamente? In: BORBA, M. C.; ARAÚJO, J. L. (Org.). Pesquisa qualitativa em Educação Matemática. Belo Horizonte: Autêntica, 2004. p. 47-76.

FULLAN, M; HARGREAVES, A. Por que vale a pena lutar? O trabalho de equipe na Escola. Porto: Porto Editora, 2001.

GOMES, S.S. Tessituras docentes de avaliação formativa. 2003. Dissertação (Mestrado em Educação) - Faculdade de Educação, Universidade Federal de Minas Gerais, Belo Horizonte, 2003.

HARGREAVES, A. Os professores em tempos e mudança: o trabalho e a cultura dos professores na idade Pós-Moderna. Portugal: McGraw-Hill, 1998. 308 p.

LESSARD, C. La collaboration au travail: des finalités à débattre entre la formulation d'une norme professionnelle et le développement d'une pratique. In: BIRON, D.; CIVIDINI, M.; 
DESBIENS, J-F. La profession enseignante aux temps de réformes. Sherbrooke: Éditions du CRP, 2005. p. 435-458.

LIMA, E. Ciclos de formação: uma reorganização do tempo escolar. São Paulo: GEDH, 2000.

LOES, V. W. Collaboration and teacher's perception of professionality in schools for secondary education. The Educational Resources Information Center (ERIC), United States of America, Department of Education, 1999.

MARX, K. O capital: crítica da economia política. São Paulo: Abril Cultural, 1983. v. 3.

MÉRINI, C. Lês dynamiques collectives dans lê travail enseignant: du mythe à l'analyse d'une réalité. In: MARCEL, J.; DUPRIEZ, V.; BAGNOUD.D; TARDIF.M. Coordonner, collaborer, coopérer: de nowvelles pratiques enseignantes. 1 ed. De Boeck, 2007.

MIRANDA, G. V. Experiência de Gestão na Secretaria Municipal de Belo Horizonte. In: OLIVEIRA, D. A. e DUARTE, M. R. T. Politica e Trabalho na Escola: Administração dos sistemas públicos de educação básica. Belo Horizonte: Autêntica, 1999, p.157-176.

OLIVEIRA, D. A.; ASSUNÇÃO, A. A. Condições de trabalho docente. In: OLIVEIRA, D. A.; DUARTE, A. M. C.; VIEIRA, L. M. F. Dicionário: trabalho, profissão e condição docente. Belo Horizonte: UFMG/Faculdade de Educação, 2010. (CD-ROM)

OLIVEIRA, L. H. R. Trabalho coletivo em Educação: os desafios para a construção de uma experiência educacional fundamentada na cooperação em uma escola municipal de São Paulo. Dissertação (Mestrado em Educação) - Faculdade de Educação, Universidade de São Paulo, São Paulo, 2006.

ROCHA, M. C. Politicas de valoriz̧ação do magistério: remuneração, plano de carreira, condições de trabalho: uma análise da experiência de Belo Horizonte. 2009. Tese (Doutorado) Universidade de São Paulo, São Paulo, 2009.

SILVA, M. Desenvolvendo as relações interpessoais no trabalho coletivo de professores. In: ALMEIDA, L. R.; PLACCO V. M. (Orgs.). As relações interpessoais na formação de professores. São Paulo: Loyola, 2002.

TARDIF, M.; LESSARD, C. O trabalho docente: elementos para uma teoria da docência como profissão de interações humanas. Petrópolis: Vozes, 2005.

TUPINAMBÁS, G. Boletim volta com conceito nas escolas municipais de BH. Estado de Minas, Belo Horizonte, 26 mar. 2009. Disponível em: <http://wwo.uai.com.br/UAI/html/ sessao_2/2009/03/26/em_noticia_interna,id_sessao=2 \&id_noticia $=104054 /$ em_noticia_ interna.shtml>. Acesso em: 30 mar. 2010.

Ensino de metas sepulta Escola Plural em BH. Estado de Minas, Belo Horizonte, 26 mar. 2009b. Disponível em: <http://ww.uai.com.br/UAI/html/sessao_2/2009/03/26/ em_noticia_interna,id_sessao $=2 \& i$ d_noticia $=104043 / \mathrm{em} \_n o t i c i a \_i n t e r n a . s h t m l>$. Acesso em: 30 mar. 2010.

VAN WESSUM, L. Collaboration and teacher's perception of professionality in schools of secondary education. In: ANNUAL MEETING OF THE AMERICAN EDUCATION RESEARCH ASSOCIATION. Paper: Montreal, Qc, Canadá: [s.n.], Apr. 1999. p. 19-23.

VARANI. A. Da constituição do trabalho docente coletivo: re-existência docente na descontinuidade das políticas educacionais. 2005. Tese (Doutorado em Educação) - UNICAMP, Campinas, 2005.

VICENTINI, A. A. F. O trabalho coletivo docente: contribuições para o desenvolvimento profissional dos professores. 2006. Dissertação (Mestrado em Educação) - UNICAMP, Campinas, 2006. 


\section{NOTAS}

${ }^{1}$ Competência aqui é entendida como "a capacidade de agir em situações complexas mobilizando saberes e conhecimentos (...). [O] aluno deve se situar no centro de seu próprio processo de aprendizagem segundo uma visão construtivista e reflexiva do ensinoaprendizagem, e os professores devem coordenar o seu trabalho visando ao desenvolvimento gradual e processual de competências ao longo de todo o processo de escolarização". (BORGES, 2010, p. 03)

${ }^{2} \mathrm{~A}$ intensificação do trabalho docente ocorre quando se exige um esforço maior do trabalhador individualizado ou do coletivo de trabalhadores - diante de uma carga adicional ou de tarefas mais complexas, ou seja, trabalhar mais densamente, ou simplesmente trabalhar mais, podendo constituir-se tanto em esforço físico, intelectual, psíquico, como também uma junção desses. A categoria intensificação do trabalho é reservada para descrever o fenômeno que reúne distintas formas e maneiras de fazer com que o trabalhador produza resultados quantitativa ou qualitativamente superiores, mantidas constantes as condições técnicas, a jornada e o número de trabalhadores (DAL ROSSO, 2006).

${ }^{3}$ A pesquisa de campo foi desenvolvida durante o $1^{\circ}$ e o $2^{\circ}$ semestres de 2010 , em duas escolas da RMEBH, tendo sido realizadas 16 entrevistas com professores regentes, além da participação da direção e da coordenação pedagógica de cada escola.

${ }^{4}$ Este período abarca a implantação do Projeto Escola Plural na Rede Municipal de Educação de Belo Horizonte (1993), que será apresentado na segunda e na terceira seções deste artigo, e a proposição de um modelo de escola mais voltado para resultados que começa a ficar mais delineado em 2009, a partir da primeira gestão do prefeito Márcio Lacerda (2009-2012). ${ }^{\mathbf{5}}$ DAL ROSSO, S. Intensidade no trabalho docente. Anotações da palestra proferida na mesa-redonda "Trabalho docente: impactos na grad uação e pós-graduação". GT 11: POLÍTICA DE EDUCAÇÃO SUPERIOR. Caxambu: ANPED, 2010.

${ }^{6}$ Trata-se de uma nova forma flexibilizada de gerir a produção, constituída pelo modo de produção capitalista e caracterizando-se pela produção voltada à demanda do consumo; a heterogeneidade e a diversidade na produção; o trabalho operário em equipe e a flexibilidade nas fu nções, visando à intensificação da exploração sobre a força de trabalho; um melhor aproveitamento do tempo, com estoque mínimo e terceirização de parte da produção; diferindo-se do modelo taylorista/fordista de produção, baseado na produção de mercadorias padronizadas (ANTUNES, 1999).

${ }^{7} \mathrm{O}$ padrão de acumulação taylorista surgiu no início do século XX, iniciado por Frederick Winslon Taylor (1856-1915) e utilizado por Henry Ford (1863-1947), no intuito de adaptar $\mathrm{o}$ trabalhador às necessidades do capital por meio do controle do processo de trabalho. $\mathrm{O}$ taylorismo dedicou-se a estudar formas de organizar melhor o trabalho, para que ele tivesse o maior rendimento possível. Elaboraram-se os fundamentos da organização dos processos de trabalho a fim de exercer maior controle e disciplina sobre os trabalhadores. Entre as propostas do chamado taylorismo estão o controle hierarquizado do processo de trabalho por meio de uma camada social de administradores, a divisão entre trabalho intelectual e manual, entre concepção e execução, em que o trabalho cerebral deve restringir-se ao departamento de planejamento e controle. Henry Ford (1863-1947) aplicou e desenvolveu os princípios de Taylor, introduzindo a linha de montagem, que gerou produtividade ainda maior do trabalho, por meio do funcionamento ininterrupto, da parcelarização das atividades e da automatização do trabalho (OLIVEIRA, 2006). 
${ }^{8}$ Mérini (2007) considera frágeis as noções de trabalho em equipe e parceria, já que as análises efetuadas sobre essas conceituações têm se demonstrado superficiais, pouco detalhadas e de pequena produtividade. O conceito de trabalho em conjunto é mais propício, visto que envolve negociação, ação comum e corresponsabilidade no desenvolvimento do trabalho. $\mathrm{O}$ trabalho conjunto remete à expressão em latim cum-laborare, que significa trabalhar com, e é orientado por um objetivo comum envolvendo sempre a resolução de um problema (MÉRINI, 2007). ${ }^{9}$ Para aprofundamento sobre o Projeto Escola Plural da RMEBH, ver MIRANDA, G. V. (1999).

${ }^{10} \mathrm{~A}$ discussão sobre a reorganização do tempo escolar mostrando o que muda na sua configuração com o Projeto da Escola Plural, principalmente no que se refere ao tempo coletivo, será desenvolvida na próxima seção.

${ }^{11}$ De acordo com o jornal Estado de Minas (2009b), esses conceitos variam de A a E e avaliam as atitudes e os valores das crianças e dos adolescentes em sala de aula, referentes à capacidade de organização do material escolar, ao zelo pelos objetos coletivos, ao interesse em aprender e emitir opiniões, ao comprometimento com a apresentação de atividades e ao cumprimento de regras e horários, à habilidade de trabalhar em equipe e saber ouvir e respeitar os colegas.

12 A partir da Lei Municipal 10.671/2013, são admitidas a licença-maternidade, a licençapaternidade e as licenças médicas por motivo de acidente em serviço e para tratamento de saúde, estas duas últimas, limitadas ao período correspondente à duração da licençamaternidade, para direito ao abono.

${ }^{13}$ Em liminar de 27 de março de 2014, o juiz determina a suspensão de processos administrativos disciplinares que tenham por objeto apurar recusas dos professores em substituir colegas faltosos durante o horário dedicado ao planejamento das atividades escolares (ACPATE). Determina também que o município se abstenha de obrigar os professores a substituírem colegas faltosos durante o horário dedicado ao planejamento de suas atividades escolares (ACPATE), sob pena de multa diária, crime de desobediência e eventual improbidade administrativa.

Recebido: $14 / 05 / 2013$

Aprovado: 21/08/2014

Contato:

Universidade Federal de Minas Gerais

Faculdade de Educação.

Av. Antônio Carlos, 6627 Pampulha

Belo Horizonte | MG | Brasil

CEP 31.270-901 